\title{
Obituary
}

\section{Stefan Grimm, 1963-2014, a tragic loss for the scientific community}

\author{
Cell Death and Differentiation (2015) 22, 247; doi:10.1038/cdd.2014.196
}

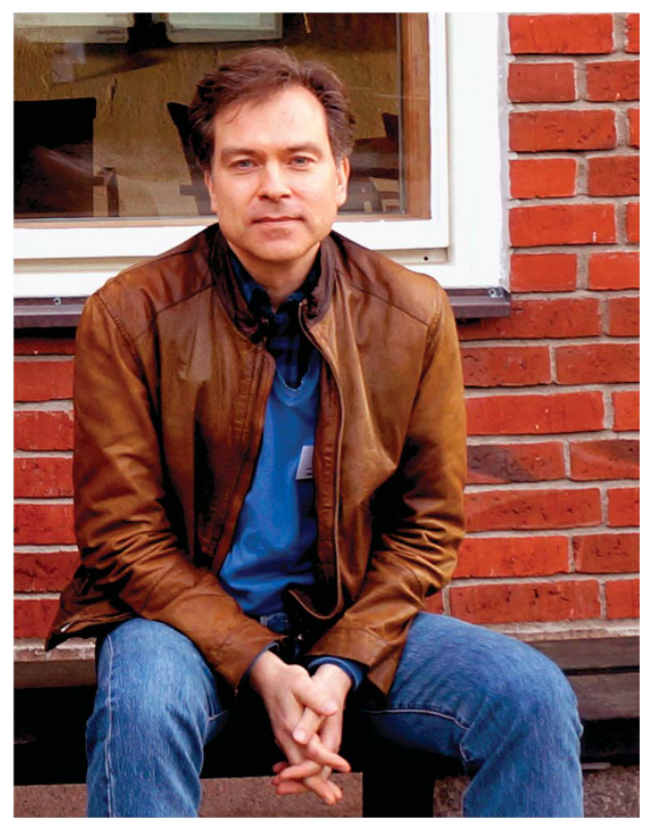

The sudden and unexpected passing of Dr Stefan Grimm, Professor of Toxicology at Imperial College in London, at the age of 51 , will leave a deep mark on our scientific community, his colleagues and family.

Dr Stefan Grimm dedicated his entire career to deciphering the molecular mechanisms involved in apoptotic cell death.

Stefan completed his $\mathrm{PhD}$ in biology working on the role of $\mathrm{NF} K \mathrm{~B}$ in cell transformation and apoptosis at Eberhard-Karls University of Tübingen, Germany in 1994.

In 1995, he started his research fellowship in the laboratory of Dr Philip Leder at the department of Genetics at the Harvard Medical School. During his 3 years there, he continued his work on the NFKB signalling pathways while simultaneously beginning to conceive new technological approaches for analysing gene functionality.

In 1998, just 4 years after completion of his PhD, Stefan moved back to Germany to launch his independent research group at the department of Biochemistry at Max-Planck Institute, Munich/ Martinsried. He succeeded in developing a robotic highthroughput assay for isolating apoptosis-inducing genes. Soon after, he co-founded Xantos Biomedicine AG, a leading functional biology and drug discovery company and served on its scientific advisory board until 2006.

Since 2004, he has been Professor of Toxicology at Imperial College in London. During the last 10 years, he contributed towards bringing to light fundamental insights into the molecular and cellular mechanisms underlying apoptotic cell death and how the dysregulation of this process can promote cancers. He notably revealed a novel class of genes with the ability to specifically target human cancers, and these he named the anti-cancer genes.

Over the past 20 years, his work to this scientific field includes 50 publications in top-ranked journals, two books, more than 3000 citations and 5 patents on innovative strategies for screening novel genes involved in cell death pathways and new anti-cancer genes. Professor Stefan Grimm chaired and co-organized international conferences and served as reviewer for research-funding organizations and many international scientific journals. Recently, Stefan was elected as fellow of the Society of Biology.

Well beyond these contributions to the scientific world, Professor Stefan Grimm was a very talented and passionate scientist and a great man to work for.

Stefan succeeded to manage a team of highly motivated and enthusiastic people coming from 14 different countries of origin. Despite this cultural diversity, he managed to create a very cohesive group that shared his love for science.

$\mathrm{He}$ was also a terrific mentor, deeply committed to all the projects running in his lab. He worked very hard, seven days a week, to prepare new grant applications for innovative research and to make sure that all of his lab members were successful in publishing high-quality research. He provided strong recommendation letters and never hesitated to make phone calls to help his trainees to get good jobs afterwards or to advance their careers. Despite his discreet and reserved personality, Stefan was a very gentle and caring person, a man of his word, working tirelessly for his students and postdoctoral scientists.

Professor Stefan Grimm will be greatly missed by his current and former lab members, colleagues and collaborators around the world.

Our hearts are saddened by his sudden loss and we would like to offer our sincere condolences to his family and friends.

The Apoptosis Group (2005-2013):

Ghada Abuali, Christoph Datler, Wanwisa Chaisaklert, Laurence Huc, Ming Hwang, Shazia Irshad, Ryota Iwasawa, Anthony Lemarie, Bevan Lin, Anne-Laure Mahul-Mellier, Foy Osborne and Evangelos Pazarentzos.

\section{A-L Mahul-Mellier ${ }^{1}$, L Huc $^{2}$, A Lemarié $^{3}$, S Irshad ${ }^{4}$, $M$ Hwang $^{5}, C$ Datler $^{5}$ and $E$ Pazarentzos ${ }^{6}$}

${ }^{1}$ BMI, EPFL, Station 19, Al 2149 (Batiment Al), CH-1015 Lausanne, Switzerland; ${ }^{2}$ INRA, TOXALIM (Research Centre in Food Toxicology), 180 chemin de Tournefeuille, F-31027 Toulouse, France; ${ }^{3}$ INSERM U1037 - Cancer Research Center of Toulouse (CRCT), Department of Experimental Therapeutics, Institut Claudius Regaud, Toulouse, France; ${ }^{4}$ Wellcome Trust Centre for Human Genetics, University of Oxford, Oxford, UK; ${ }^{5}$ Division of Experimental Medicine, Imperial College London, London, UK and ${ }^{6} \mathrm{Helen}$ Diller Family Comprehensive Cancer Center, University of California San Francisco, San Francisco, CA, USA E-mail: anne-laure.mahul@epfl.ch 